\title{
Repurposing mesalazine against cardiac fibrosis in vitro
}

\author{
Maximilian Hoffmann ${ }^{1} \cdot$ Theresa A. Kant ${ }^{1} \cdot$ Ramona Emig $^{2,3,4,5} \cdot$ Johanna S. E. Rausch $^{1} \cdot$ Manja Newe ${ }^{1}$. \\ Mario Schubert ${ }^{1} \cdot$ Karolina Künzel $^{1} \cdot$ Luise Winter $^{1} \cdot$ Erik Klapproth $^{1} \cdot$ Rémi Peyronnet $^{2,3}$ • Ursula Ravens ${ }^{2}$. \\ Ali El-Armouche ${ }^{1}$ · Stephan R. Künzel ${ }^{1}$ (1)
}

Received: 18 September 2020 / Accepted: 8 October 2020 / Published online: 16 October 2020

(C) The Author(s) 2020

\begin{abstract}
Cardiovascular diseases are exacerbated and driven by cardiac fibrosis. TGF $\beta$ induces fibroblast activation and differentiation into myofibroblasts that secrete excessive extracellular matrix proteins leading to stiffening of the heart, concomitant cardiac dysfunction, and arrhythmias. However, effective pharmacotherapy for preventing or reversing cardiac fibrosis is presently unavailable. Therefore, drug repurposing could be a cost- and time-saving approach to discover antifibrotic interventions. The aim of this study was to investigate the antifibrotic potential of mesalazine in a cardiac fibroblast stress model. TGF $\beta$ was used to induce a profibrotic phenotype in a human cardiac fibroblast cell line. After induction, cells were treated with mesalazine or solvent control. Fibroblast proliferation, key fibrosis protein expression, extracellular collagen deposition, and mechanical properties were subsequently determined. In response to TGF $\beta$ treatment, fibroblasts underwent a profound phenoconversion towards myofibroblasts, determined by the expression of fibrillary $\alpha$ SMA. Mesalazine reduced differentiation nearly by half and diminished fibroblast proliferation by a third. Additionally, TGF $\beta$ led to increased cell stiffness and adhesion, which were reversed by mesalazine treatment. Collagen 1 expression and deposition - key drivers of fibrosis - were significantly increased upon TGF $\beta$ stimulation and reduced to control levels by mesalazine. SMAD2/3 and ERK1/2 phosphorylation, along with reduced nuclear NFKB translocation, were identified as potential modes of action. The current study provides experimental pre-clinical evidence for antifibrotic effects of mesalazine in an in vitro model of cardiac fibrosis. Furthermore, it sheds light on possible mechanisms of action and suggests further investigation in experimental and clinical settings.
\end{abstract}

Keywords Myofibroblasts $\cdot$ Collagen $\cdot$ Phenoconversion $\cdot$ Cytoskeleton $\cdot$ Fibrosis mechanisms

Maximilian Hoffmann, Theresa A. Kant and Ramona Emig contributed equally to this work.

Electronic supplementary material The online version of this article (https://doi.org/10.1007/s00210-020-01998-9) contains supplementary material, which is available to authorized users.

Stephan R. Künzel

stephan.kuenzel@tu-dresden.de

1 Institute of Pharmacology and Toxicology, Faculty of Medicine Carl Gustav Carus, Technische Universität Dresden, Fiedlerstraße 42, 01309 Dresden, Germany

2 Institute for Experimental Cardiovascular Medicine, University Heart Center Freiburg-Bad Krozingen, Medical Center-University of Freiburg, Freiburg, Germany

3 Faculty of Medicine, University of Freiburg, Freiburg, Germany

4 CIBSS Centre for Integrative Biological Signalling Studies, University of Freiburg, Freiburg, Germany

5 Faculty of Biology, University of Freiburg, Freiburg, Germany

\section{Introduction}

Fibrosis is the excessive deposition of extracellular matrix (ECM) proteins, leading to organ dysfunction, morbidity and finally death. Worldwide, the burden of fibrosis is substantial, as $25 \%$ of the population are affected and approximately $45 \%$ of deaths in the Western world can be attributed to diseases involving fibroproliferation (Artlett 2012; Zhao et al. 2020).

The human heart is particularly vulnerable to fibrotic remodeling, as lost cardiomyocytes do not regenerate and thus are replaced by ECM proteins (Uygur and Lee 2016). Therefore, most cardiovascular diseases are accompanied by fibrosis (Murtha et al. 2017; Hinderer and SchenkeLayland 2019). In health, cardiac fibroblasts safeguard the ECM homeostasis by well-balanced secretion and degradation of ECM proteins, ensuring optimal tissue mechanical properties. Thereby, they protect the heart from rupture due to high mechanical load without negatively 
affecting cardiac function (Tallquist and Molkentin 2017). In disease, however, activating stimuli such as transforming growth factor beta 1 (TGF $\beta$ ) induce a phenotypic transition of fibroblasts towards $\alpha$-smooth muscle actin ( $\alpha$ SMA)-positive myofibroblasts (Baum and Duffy 2011; Tallquist and Molkentin 2017), which excessively secrete collagen and release cytokines leading to local inflammation, cardiac dysfunction, and arrhythmias such as atrial fibrillation (Jalife and Kaur 2015; Künzel et al. 2020).

Recent clinical therapeutic approaches towards cardiac fibrosis concentrate on the modulation of the reninangiotensin-aldosterone system with angiotensinconverting enzyme inhibitors, angiotensin-II receptor subtype-1 blockers, and aldosterone or renin inhibitors (Jia et al. 2018; Park et al. 2019). Furthermore, inflammation modulators targeting tumor necrosis factor alpha (e.g., infliximab), statins like rosuvastatin and peroxisomal proliferator-activated receptor agonists like fenofibrate have been tested to ameliorate cardiac fibrosis but failed to provide convincing results in several clinical studies (Fang et al. 2017). As of today, there are no drugs available that reliably prevent or substantially reverse fibrosis (Zhao et al. 2020).

Current research has focused on the experimental modulation of the TGF $\beta$, extracellular signal-regulated kinases 1 and 2 (ERK1/2), and SMAD2/3 pathways in cardiac (myo)fibroblasts (Evans et al. 2003; Fan and Guan 2016; Khalil et al. 2017; Luo et al. 2017). Given the substantial costs and extensive timeline of de novo drug development to specifically modulate these pathways, repurposing of established compounds with known safety profiles could be an attractive and low-risk approach to providing antifibrotic therapy (Paul et al. 2010; Sertkaya et al. 2016; Pushpakom et al. 2019).

Aminosalicylates, like aspirin, have shown promising results in the experimental treatment of cardiac fibrosis (Liu et al. 2017). However, the translational value of this finding might be limited because dose-dependent systemic side effects such as bleeding or gastric ulcer are common with aspirin (Weil et al. 1995; Huang et al. 2011). Mesalazine (5-aminosalicylic acid) is structurally comparable to aspirin (Desreumaux and Ghosh 2006), but can be administered in high daily doses with good tolerability (Clemett and Markham 2000). While its mode of action is still under debate, experimental evidence suggests that orally administered mesalazine reduces the expression of profibrotic cytokines (Ramadan et al. 2018), predisposing the compound for further investigation into antifibrotic drug repurposing. In this study, we investigate the effect of mesalazine on fibrotic phenotype conversion of cardiac fibroblasts, using a previously described in vitro model (Künzel et al. 2020).

\section{Materials and methods}

\section{Cell culture}

All experiments were performed with the recently in-house developed human atrial fibroblast cell line HAF-SRK01 (HAF) (Künzel et al. 2020) (RRID:CVCL ZG36). Cells were cultured under controlled conditions $\left(37{ }^{\circ} \mathrm{C}, 90 \%\right.$ humidity, $5 \% \mathrm{CO}_{2}$ ) in non-coated cell culture dishes (Sigma-Aldrich; USA; Techno Plastic Products, Switzerland) containing as culture medium Dulbecco's modified Eagle's medium with high glucose $(4500 \mathrm{mg} / \mathrm{L}$; Sigma-Aldrich, USA), $10 \%$ fetal calf serum, and $1 \%$ penicillin-streptomycin.

\section{TGF $\beta$ stress model and mesalazine treatment protocol}

TGF $\beta$ is one of the most potent inductors of virtually all types of fibrosis (Rockey et al. 2015). Unless stated otherwise, $24 \mathrm{~h}$ after seeding, the cells were stimulated with TGF $\beta$ (10 ng/mL in medium) (100-21C, Peprotech, USA) for $72 \mathrm{~h}$, followed by either $72 \mathrm{~h}$ of medium (solvent control) or $10 \mathrm{mmol} / \mathrm{L}$ mesalazine (A3537, Sigma-Aldrich, USA) solved in medium (Fig. 1). TGF $\beta$ treatment followed by solvent control is stated as "TGF $\beta$ " in the results, whereas TGF $\beta$ treatment followed by mesalazine is stated as "TGF $\beta$ + Mesa." Medium and drugs (TGF $\beta$ and mesalazine) were changed daily.

\section{Functional fibroblast characterization}

Proliferation As described above, $1 \times 10^{4}$ cells/well were seeded in 12-well plates with daily change of medium and drugs. Cells were harvested and counted after 5 and 10 days using $0.25 \%$ trypsin and a Buerker counting chamber. Results were calculated as cells $\times 10^{4} / \mathrm{mL}$.

Myofibroblast differentiation To evaluate myofibroblast differentiation, immunocytochemistry (ICC) for fibrillary $\alpha$ SMA was conducted as described previously (Poulet et al. 2016; Künzel et al. 2019). For this purpose, $0.5 \times$ $10^{4}$ cells/well were seeded on glass coverslips in 24 -well plates. Stimulation and treatment were performed as described above. Pictures of independent coverslips were randomly taken and the percentage of myofibroblasts was calculated in relation to the total number of counted nuclei. A minimum of 50 cells/coverslip was analyzed. Table 1 provides the primary and secondary antibodies that were used to detect the proteins of interest.

NFKB translocation Cells $\left(0.5 \times 10^{4} /\right.$ well $)$ were seeded on coverslips in $24-w e l l$ plates. The next day, the cells were cultured in drug-free medium as a control or stimulated 


Control

Fig. 1 Schematic illustration of the TGF $\beta$ stress model and mesalazine treatment protocol

with TGF $\beta(10 \mathrm{ng} / \mathrm{mL})$ for $1 \mathrm{~h}$, followed by drug-free medium or mesalazine $(10 \mathrm{mmol} / \mathrm{L})$ for an additional $2 \mathrm{~h}$. After fixation, cells were permeabilized using Triton-X $100(0.5 \%)$. Subsequently, ICC for NFkB was performed and nuclei were stained with DAPI. To evaluate the nuclear translocation of $\mathrm{NFKB}$, images were quantified using CellProfiler ${ }^{\mathrm{TM}}$-Software (Broad Institute, Cambridge, USA) (McQuin et al. 2018). The results are presented as nuclear NFKB intensity normalized to nuclear area per analyzed cell.

\section{Collagen secretion and deposition}

For assessment of collagen deposition on the growth surface, cells were first seeded on glass coverslips in standard culture medium at a density of $10 \times 10^{4}$ cells $/ \mathrm{cm}^{2}$. Twenty-four hours after seeding, the medium was changed to DMEM high glucose supplemented with $0.5 \%$ FCS, $1 \%$ penicillin/streptomycin, $0.5 \mathrm{mmol} / \mathrm{L}$ ascorbic acid (AAcid), and the indicated drugs. After $48 \mathrm{~h}$, cells were fixed in $4 \%$ para-formaldehyde. Deposited collagen was visualized using ICC against collagen I $\alpha 1$. Imaging was performed on a Leica SP8X line-scanning confocal microscope using a $\times 40$ water-immersion objective. For image analysis, an in-house macro for FIJI (Schindelin et al. 2012) was used. In short, a maximal intensity projection of all planes was performed after background subtraction. A uniform intensity-based threshold was then used to identify the collagen-positive area. The overall collagen-covered area was then normalized to the number of nuclei in the respective image.

Table 1 Antibodies

\begin{tabular}{|c|c|c|c|c|}
\hline Protein & Dilution & $\begin{array}{l}\text { Conjugate/ } \\
\text { source }\end{array}$ & Product-Nr. & Usage \\
\hline \multicolumn{5}{|l|}{ Primary antibodies } \\
\hline$\alpha \mathrm{SMA}$ & $\begin{array}{l}1: 200(\text { ICC) } \\
1: 1000(\mathrm{WB})\end{array}$ & Mouse & A5228 & $\mathrm{ICC}^{1}$ and $\mathrm{WB}^{2}$ \\
\hline Collagen 1 & $1: 10.000$ & Rabbit & ab34710 & WB \\
\hline SMAD $2 / 3$ & $1: 1000$ & Rabbit & \#3102 & WB \\
\hline Phospho-SMAD 2 & $1: 1000$ & Rabbit & \#8828 & WB \\
\hline ERK 1/2 (p42/44) & $1: 1000$ & Rabbit & \#9102 & WB \\
\hline Phospho-ERK 1/2 (p42/44) & $1: 1000$ & Rabbit & \#9101 & WB \\
\hline EEF2 & $1: 50.000$ & Rabbit & ab40812 & WB \\
\hline GAPDH & $1: 50.000$ & Mouse & sc-365062 & WB \\
\hline Collagen 1 A1 & $1: 100$ & Goat & MBS316282 & ICC \\
\hline NFKB (p65) & $1: 400$ & Rabbit & $8242 \mathrm{~s}$ & ICC \\
\hline \multicolumn{5}{|l|}{ Secondary antibodies } \\
\hline Goat-anti-mouse & $1: 10.000$ & Peroxidase & A3682 & WB \\
\hline Goat-anti-rabbit & $1: 10.000$ & Peroxidase & $111-035-045$ & WB \\
\hline Alexa fluor 546 (goat-anti-mouse) & $1: 400$ & Streptavidin & Z25004 & ICC \\
\hline Alexa fluor 546 (goat-anti-rabbit) & $1: 400$ & Streptavidin & Z25304 & ICC \\
\hline Alexa fluor 555 (donkey-anti-goat) & $1: 500$ & None & A32816 & ICC \\
\hline
\end{tabular}

${ }^{1}$ Immunocytochemistry

${ }^{2}$ Western blot 
Fig. 2 Mesalazine reduces TGF $\beta$-induced myofibroblast differentiation and fibroblast proliferation. a Quantification of myofibroblast differentiation in HAF by immunohistochemical assessment of $\alpha$ SMA myofilaments (red). Myofibroblast differentiation was induced with 10 $\mathrm{ng} / \mathrm{mL} \mathrm{TGF} \beta$ for $72 \mathrm{~h}$.

Subsequently cells were treated with mesalazine or solvent control ( $5 \leq n \leq 8$-independent coverslips). b Representative immunofluorescence images for fibrillary $\alpha \mathrm{SMA}$ (red), nuclei were stained with DAPI (blue), scale bars $=20 \mu \mathrm{m}$. c Fibroblast proliferation curves under control conditions and with $10 \mathrm{mmol} / \mathrm{L}$ mesalazine treatment which was continuously applied for the duration of the experiment ( $n=6$ per condition). Cells were harvested and counted after 5 and 10 days. The cell count was calculated in a resuspension volume of $1 \mathrm{~mL}$ a

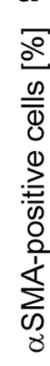

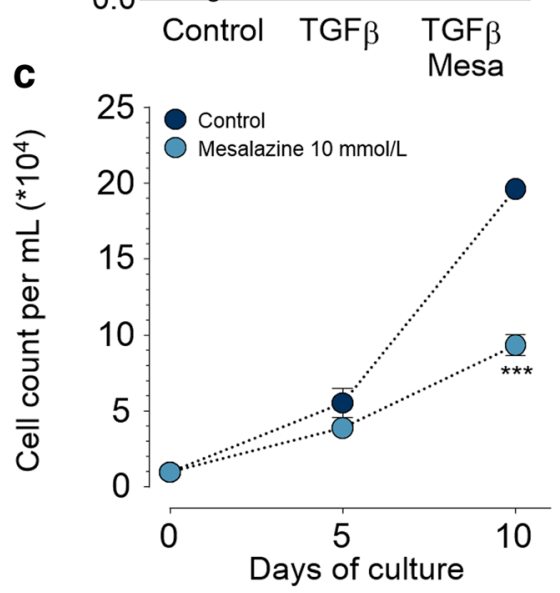

b
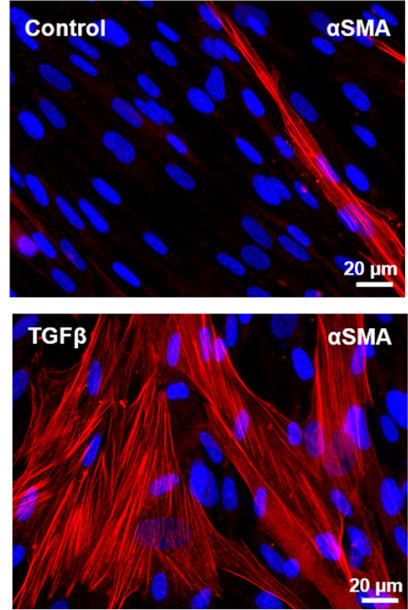

TGF $\beta+$ Mesalazine

\section{Cell mechanical properties}

\section{SDS-PAGE, western blotting, and immunodetection}

The mechanical properties of cells in response to the indicated treatments were assessed using the Chiaro nanoindenter system (Optics11, Amsterdam, the Netherlands) as described previously (Emig et al. 2019). Briefly, a spherical tip with a $3-\mu \mathrm{m}$ radius, attached to a calibrated cantilever with a spring constant of 0.03 $\mathrm{N} / \mathrm{m}$, was used to indent the sample while the bending of the cantilever was tracked by interferometry (Fig. 3a). On each cell, indentations were performed at three different places, excluding the nuclear region. The force applied to the cantilever was then calculated as the product of cantilever bending and spring constant. Sample indentations of 2-4 $\mu \mathrm{m}$ were performed at a displacement speed of $5 \mu \mathrm{m} / \mathrm{s}$. The effective Young's modulus $\left(E_{\mathrm{Eff}}\right)$ was derived using a Hertzian model (red curve in Fig. 3b) for contact mechanics (Hertz 1882) under the assumption of a Poisson's ratio of 0.5 for incompressible materials, commonly used for mechanical testing of cells and tissue (Guz et al. 2014). Throughout this manuscript, $E_{\mathrm{Eff}}$ is referred to as stiffness. Additionally, stress relaxation of the cells in response to indentation was calculated from the remaining load after holding the indenter at maximal compression for $2 \mathrm{~s}$ and is given as percentage of the maximal load. Cell adhesion to the indenter tip was estimated from the maximum negative force that was recorded upon cantilever retraction. Data analysis was performed using the DataViewer software (V2.3.0, Optics11, Amsterdam, the Netherlands) and in-house MatLab scripts (R2019a).
Protein was extracted from whole-cell lysates using radioimmunoprecipitation assay buffer $(30 \mathrm{mM}$ Tris, $0.5 \mathrm{mM}$ EDTA, $150 \mathrm{mM} \mathrm{NaCl}, 1 \% \mathrm{NP}-40,0.1 \%$ SDS) supplemented with $10 \%$ protease and phosphatase inhibitors (Roche, Switzerland). To ascertain protein concentration, a bicinchoninic acid kit (Thermo Fischer, USA) was used. Western blots were performed as described previously (ElArmouche et al. 2008). A $20 \mu \mathrm{g}$ of a whole-cell protein was separated on a $10 \%$ polyacrylamide gel and then transferred to a nitrocellulose membrane. Immunodetection was performed with a Fusion FX device (Vilber Lourmat Deutschland $\mathrm{GmbH}$, Germany). Table 1 provides a list of antibodies and respective concentrations used in this study.

\section{Data analysis}

For data analysis and graphic representation, Prism 8 (GraphPad, USA) was used. Data are presented as single data points and mean \pm standard error of the mean (SEM). For comparisons between two conditions, Student's $t$ test was used with Welsh's correction if appropriate. When comparing three or more conditions, a one-way ANOVA with Tukey posttest was performed. Two means were considered significantly different with $p$ values $<0.05$. A single asterisk $(*)$, 
a

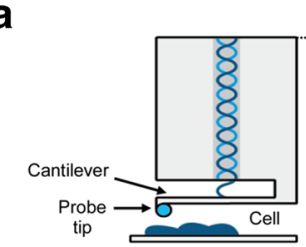

b
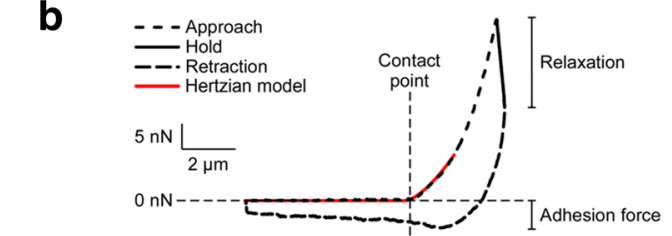

C

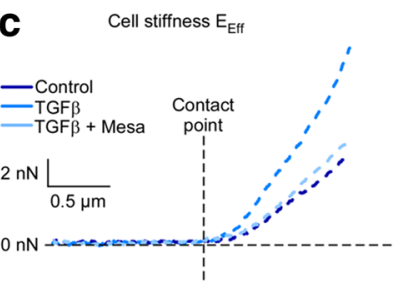

d

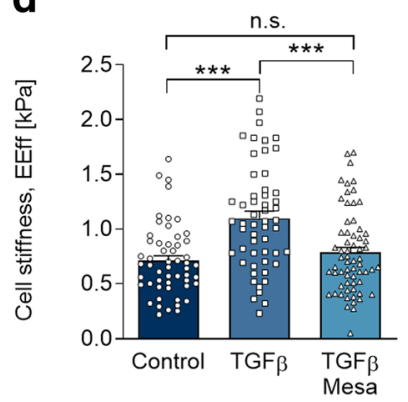

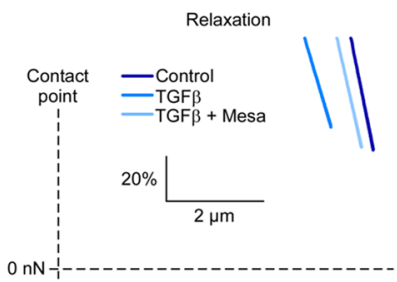
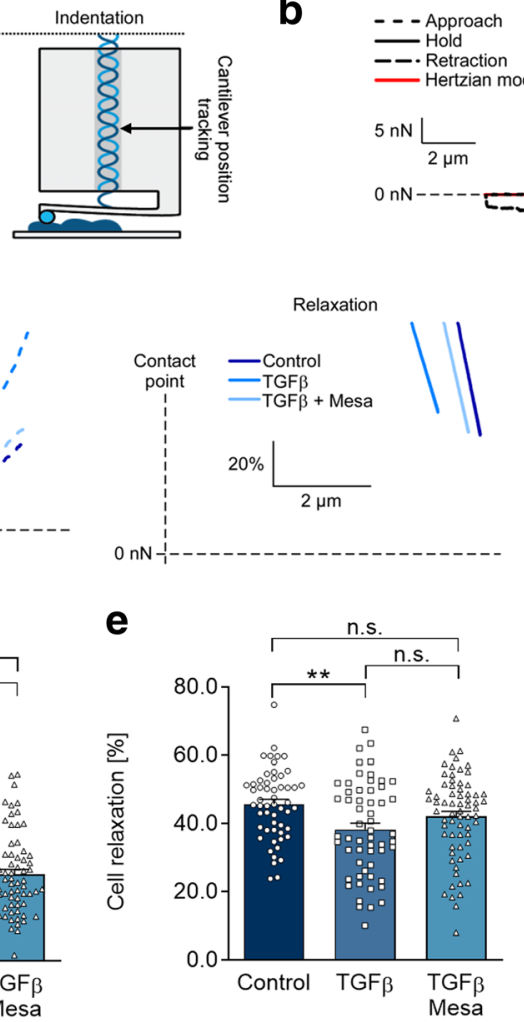

\section{f}

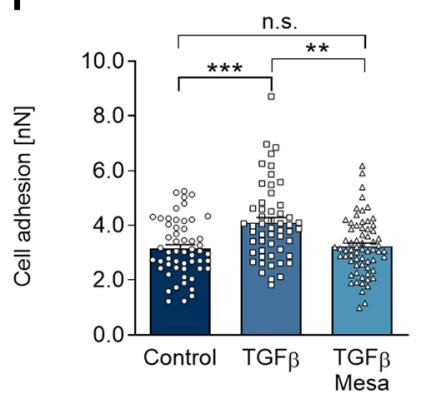

Fig. 3 Mesalazine reverses TGF $\beta$-induced changes in HAF mechanical properties. a Schematic representation of the nanoindenter probe before (left) and during (right) cell indentation, adapted from Optics11. b and c Representative load/indentation curve used to calculate cell stiffness $\left(E_{\text {eff }}\right)$, stress relaxation, and cell adhesion of individual HAF cultured under control conditions, with TGF $\beta(10 \mathrm{ng} / \mathrm{mL})$ and with TGF $\beta$ followed by mesalazine $(10 \mathrm{mmol} / \mathrm{L})$ treatment (whole curve $(b)$ and with each phase shown separately for the 3 conditions (c; note that relaxation is plotted as relative values). d Cell stiffness measured under control

double asterisk $(* *)$, and triple asterisk $(* * *)$ indicate $p$ values below $0.05,0.01$, and 0.001 , respectively.

\section{Results and discussion}

\section{Mesalazine reverses fibrotic phenotype conversion}

Resident cardiac fibroblasts are primarily responsible for the fibrotic remodeling of the heart (Khalil et al. 2017). As the availability of primary human cardiac fibroblasts is limited, we recently established the human atrial fibroblast cell line HAF-SRK01 (Künzel et al. 2020) (HAF), which was employed in this study to test potential antifibrotic effects of mesalazine. In our model, we induced a profibrotic phenotype by treating fibroblasts with $10 \mathrm{ng} / \mathrm{mL}$ TGF $\beta$, a major regulator of fibrosis (Meng et al. 2016). Myofibroblast differentiation was determined by the expression of fibrillary $\alpha \mathrm{SMA}$ which is characteristic for myofibroblasts (Baum and Duffy 2011). conditions, with TGF $\beta(10 \mathrm{ng} / \mathrm{mL})$ and with $\mathrm{TGF} \beta$ followed by mesalazine $(10 \mathrm{mmol} / \mathrm{L})$ treatment $(n=54,54$, and 62 respectively from 4 independent experiments). e Cell relaxation measured under control conditions, with TGF $\beta(10 \mathrm{ng} / \mathrm{mL})$ and with $\mathrm{TGF} \beta$ followed by mesalazine $(10 \mathrm{mmol} / \mathrm{L})$ treatment $(n=55,57$, and 67 respectively from 4 independent experiments). f Cell adhesion measured under control conditions, with TGF $\beta(10 \mathrm{ng} / \mathrm{mL})$ and with TGF $\beta$ followed by mesalazine $(10 \mathrm{mmol} / \mathrm{L})$ treatment $(n=55,54$, and 67 respectively from 4 independent experiments)

After the $72 \mathrm{~h}$ TGF $\beta$ induction phase, followed by $72 \mathrm{~h}$ in control medium, cultured fibroblasts displayed a fibrotic phenotype, as determined by ICC for fibrillary $\alpha \mathrm{SMA}$ (Fig. 2a and b): $43.6 \pm 6.5 \%$ of cells were identified as myofibroblasts, compared to $7.7 \pm 1.2 \%$ in the absence of TGF $\beta$ treatment $(p<0.001)$. This fibrotic effect of TGF $\beta$ was reduced to levels that were not significantly different from control by mesalazine treatment, to $23.0 \pm 1.8 \%(p<$ 0.05) (Fig. 2a and b).

Fibroblast proliferation is another prominent indicator of a profibrotic phenotype. In parallel to lowering $\alpha$ SMA expression, mesalazine treatment also significantly reduced proliferation to roughly half of that seen under control conditions $(P<$ 0.001; Fig. 2c).

To control cardiac fibrosis, reduction of both excess fibroblast proliferation and myofibroblast differentiation are essential (Fan and Guan 2016). Our results are in line with previous studies showing general antiproliferative effects of mesalazine in mucosal cells of the large bowel and colorectal cancer cells (Reinacher-Schick et al. 2000; 


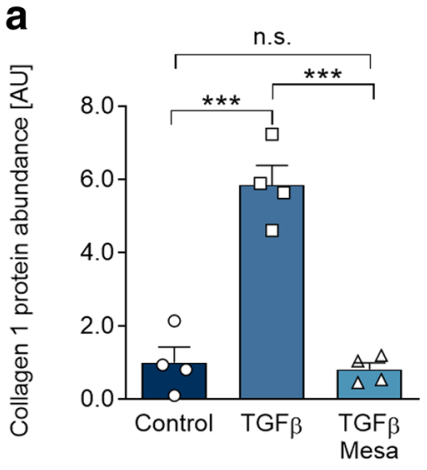

b

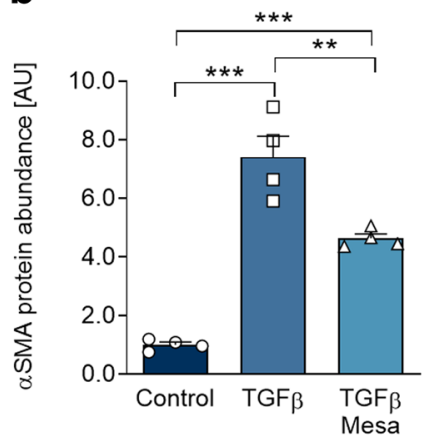

C

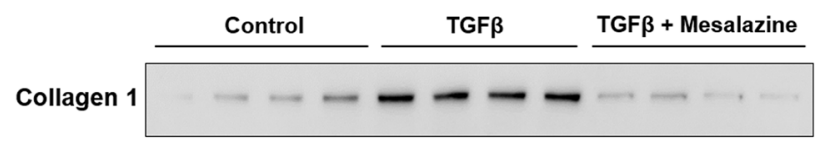

aSMA

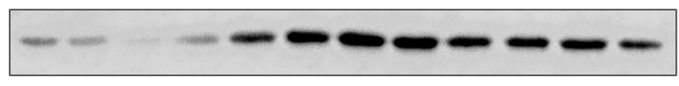

EEF2

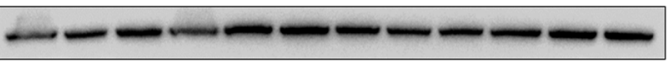

d

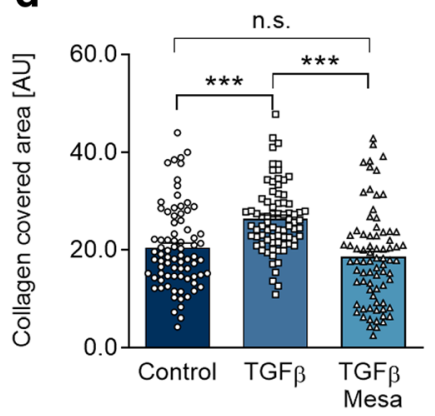

Fig. 4 Mesalazine ameliorates key fibrosis protein expression and collagen deposition after TGF $\beta$ treatment. a Quantification of collagen 1 protein expression in HAF under control conditions, TGF $\beta$ and sequential TGF $\beta$-mesalazine treatment ( $n=4$ per condition). b Quantification of $\alpha \mathrm{SMA}$ protein expression in HAF fibroblasts under control conditions, TGF $\beta$ and sequential TGF $\beta$-mesalazine treatment

Carmine Stolfi and Francesco Pallone 2008). Effects on cardiac fibroblast proliferation and differentiation were previously unknown.

\section{Mesalazine affects mechanical properties of HAF}

After finding that mesalazine treatment affects the expression of $\alpha \mathrm{SMA}$ in HAF, we aimed to assess its effect on the remodeling of the cytoskeleton from a more general perspective. To do so, we analyzed the mesalazine effects on cell mechanical properties, which depend directly on cytoskeleton composition and organization. When fibroblasts are activated, the cytoskeleton is remodeled, which contributes to a number of cell functions (Hinz et al. 2001; Hinz et al. 2019). Using nanoindentation (Fig. 3a), load indentation curves (Fig. 3b and c) were obtained and used to quantify cell stiffness, relaxation and adhesion (Fig. 3c-f) Compared to control conditions, average cell stiffness increased from 0.71 to $1.10 \mathrm{kPa}$ in response to TGF $\beta(p<0.001)$. Subsequent mesalazine treatment reduced average cell stiffness to $0.83 \mathrm{kPa}(p<0.001)$, a level not different from control conditions (Fig. $3 \mathrm{c} \mathrm{left} \mathrm{panel} \mathrm{and} \mathrm{d).}$ In line with increased cell stiffness, stress relaxation of TGF $\beta$ treated cells was lower than in control cells (38.3 vs. $45.7 \%$, respectively; $p<0.01)$. In response to mesalazine treatment, stress relaxation was not significantly different from both the control condition and TGF $\beta$, highlighting an increased scattering with more cells showing relaxation values not different from control (Fig. $3 \mathrm{c}$ middle panel and e).

Fibrosis and myofibroblast differentiation have been linked to an increased presence of cell adhesion molecules (Yoshizaki et al. 2010; Schroer and Merryman 2015). Therefore, we assessed the adhesive properties of HAF in response to TGF $\beta$ stimulation and subsequent mesalazine treatment by determining the maximal negative force that was recorded during cantilever retraction. TGF $\beta$ treatment significantly increased the adhesion to the indenter tip compared to control (3.15 nN vs. $4.19 \mathrm{nN}, p<0.001$; Fig. 3d). Mesalazine treatment reduced the adhesive force of the cells to $3.37 \mathrm{nN}(p<0.01)$, a level not significantly different from control conditions (Fig. $3 \mathrm{c}$ right panel and d).

Our findings are in keeping with previous studies relating TGF $\beta$ signaling to cell adhesion via integrin signaling (Walsh and Young 2011, p. 1).

\section{Mesalazine ameliorates key fibrosis protein expression and collagen deposition}

Collagen 1 is the predominant type of collagen in cardiac fibrosis (Zhao et al. 2020), and it was therefore used as a readout for determining the effectiveness of the antifibrotic 

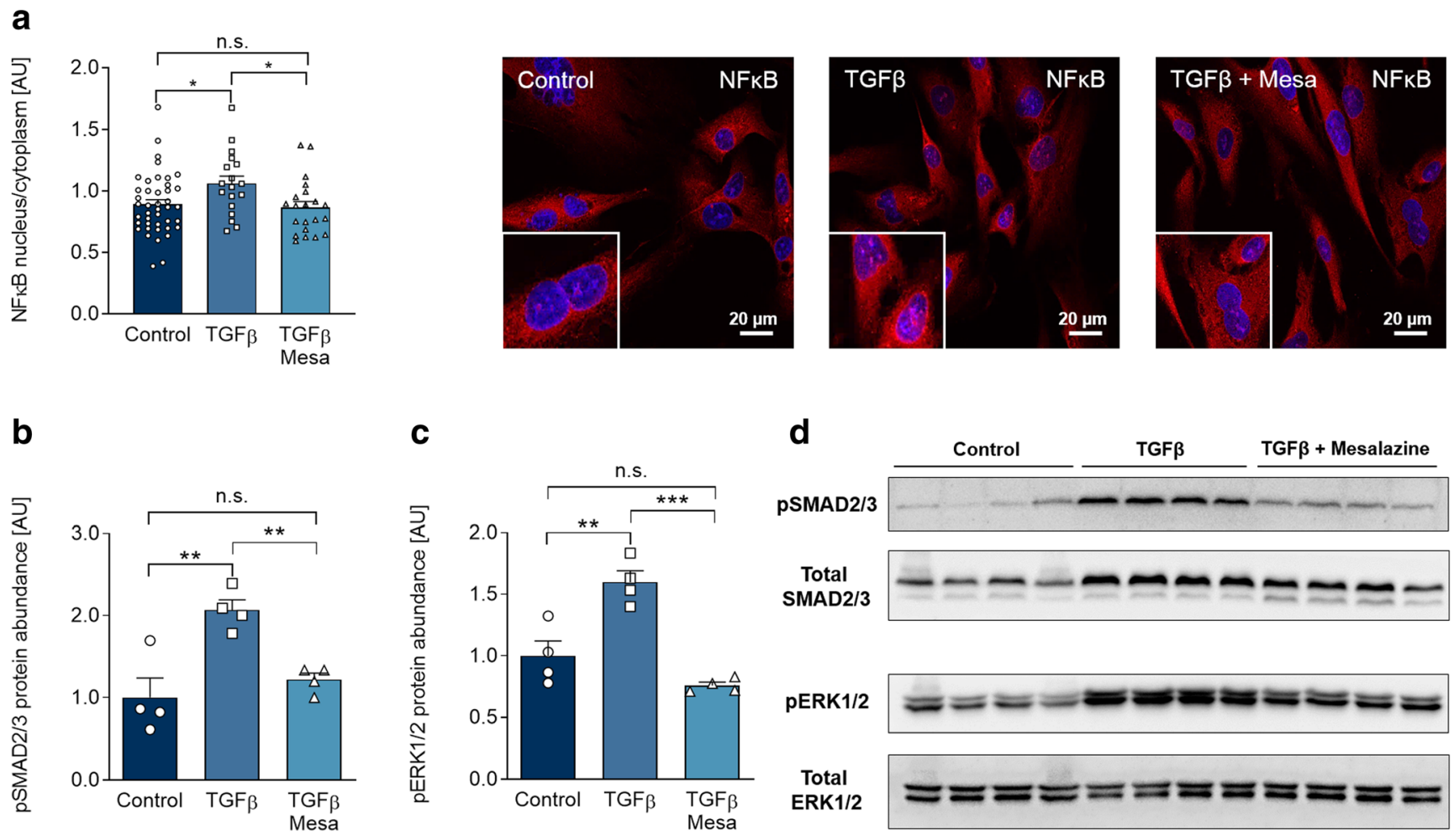

Fig. 5 Mesalazine inhibits TGF $\beta$-induced SMAD2/3 and ERK1/2 phosphorylation and reduces nuclear NFKB translocation. a Quantification and representative immunofluorescence images of NFKB (NFKB (p65) red; DAPI-stained nuclei blue) under control conditions, TGF $\beta$ and sequential TGF $\beta$-mesalazine treatment $(18 \leq n \leq 43$ cells from each 4 independent coverslips). b Quantification of SMAD2/3 phosphorylation

intervention. Having demonstrated that mesalazine reverses TGF $\beta$-induced changes in differentiation, proliferation, and cell mechanical properties, we studied the effects of mesalazine on intracellular collagen 1 and $\alpha$ SMA expression to extend the ICC observations.

TGF $\beta$ treatment led to enhanced intracellular collagen 1 and $\alpha$ SMA protein expression by approximately 6- and 8fold, respectively $(p<0.001)$. Mesalazine treatment abolished the TGF $\beta$-induced increase in HAF intracellular collagen expression $(p<0.001$; Fig. 4a-c) and reduced the level of $\alpha$ SMA protein expression $(p<0.01$, Fig. $4 \mathrm{a}-\mathrm{c})$.

Table 2 Selected adverse effects of mesalazine

\begin{tabular}{ll}
\hline Event & Frequency \\
\hline Nausea/vomiting & Common \\
Headache & Common \\
Abdominal pain & Common \\
Skin exanthema & Common \\
Interstitial nephritis & Less common \\
Pancreatitis & Less common \\
Blood dyscrasias & Rare \\
\hline
\end{tabular}

(pSMAD2/3) in HAF under control conditions, TGF $\beta$ and sequential TGF $\beta$-mesalazine treatment ( $n=4$ per condition). $\mathbf{c}$ Quantification of ERK1/2 phosphorylation (p ERK1/2) in HAF fibroblasts under control conditions, TGF $\beta$ and sequential TGF $\beta$-mesalazine treatment $(n=4$ per condition). d Representative western blots for (b) and (c)

Extracellular matrix production is a complex process and tightly regulated at different levels. After finding that mesalazine treatment reduced intracellular collagen 1 expression, we determined if the deposition of fibrillary collagen 1 in the extracellular space was affected by mesalazine. ICC further revealed that TGF $\beta$ treatment of HAF increased extracellular collagen deposition $(p<$ 0.001 , Fig. $4 d$ ), which was also abolished by subsequent mesalazine treatment ( $p<0.001$, Fig. $4 d)$.

\section{Mesalazine acts as a dual inhibitor of SMAD2/3 and ERK1/2 phosphorylation and reduces nuclear translo- cation of NFKB}

Although mesalazine has been in clinical use for decades, its mode of action is still a matter of debate. Therefore, we aimed to identify mechanisms by which mesalazine exerts its antifibrotic effects in the experimental setting of in vitro fibrosis.

Inhibition of the proinflammatory NF $\mathrm{KB}$-signaling pathway by mesalazine in inflammatory bowel disease is a widely accepted concept (Desreumaux and Ghosh 2006). We investigated whether NFKB translocation to the nucleus was affected by TGF $\beta$ and subsequent 


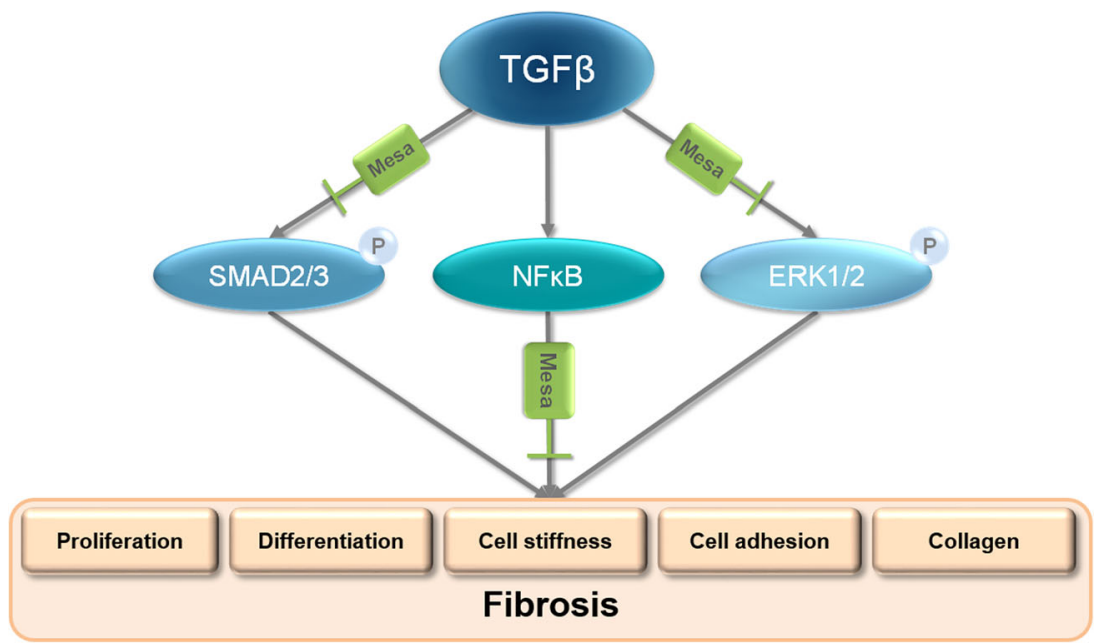

Fig. 6 Schematic illustration of mesalazine's proposed mechanism of antifibrotic action in fibroblasts. Upon stimulation with TGF $\beta$, SMAD2/3, and ERK1/2 are activated, which is reflected by increased protein phosphorylation. Additionally, $\mathrm{NF} \kappa \mathrm{B}$ translocates from the cytosol to the nucleus, where it may induce fibrotic gene expression.

mesalazine treatment in cardiac fibroblasts. In response to TGF $\beta$ stimulation, we found a significant increase in nuclear NFkB, which was restored to control levels by mesalazine $(p<0.05$, Fig. 5a). This is particularly interesting, since NFKB has been shown to induce myofibroblast differentiation and fibrosis in pulmonary and hepatic fibrosis (Luedde and Schwabe 2011; Dong and Ma 2019).

SMAD2/3 and ERK1/2 activation by TGF $\beta$ are central mechanisms of the fibrotic signaling cascade (Khalil et al. 2017; Khalil et al. 2017; Luo et al. 2017) and modulation of these pathways has been proposed to affect cardiac and non-cardiac fibrosis (Rosenbloom et al. 2013; Cheng et al. 2016; Khalil et al. 2017; Li et al. 2018). In a murine model of pressure overload, selective block of SMAD2/3 signaling drastically attenuated fibrosis (Khalil et al. 2017). Also, ERK1/2 inhibition attenuated fibrotic remodeling after myocardial infarction (Luo et al. 2017). Although the structurally similar aspirin has been shown to suppress ERK1/2 and SMAD2/3 signaling ( $\mathrm{Li}$ et al. 2018; Zhang et al. 2020), systemic side effects might overshadow the potential benefits. For this reason, we explored the effects of mesalazine on SMAD2/3 and ERK $1 / 2$ activation.

TGF $\beta$ stimulation led to a significant increase of both SMAD2/3 and ERK1/2 phosphorylation $(p<0.01$, Fig. $5 \mathrm{~b}-\mathrm{d})$. After mesalazine treatment, SMAD2/3 and ERK1/ 2 phosphorylation were reduced to control levels $(p<$ 0.01 , Fig. $5 b-d)$. These results underline the potential of repurposing mesalazine against cardiac fibrosis, as it restores $\mathrm{SMAD} / 3$, ERK1/2, and NFkB homeostasis in cardiac fibroblasts, opening up new therapeutic directions.
Together, these mechanisms lead to myofibroblast differentiation and collagen deposition, which are hallmarks of fibrosis. Mesalazine treatment inhibits SMAD2/3 and ERK1/2 phosphorylation and prevents nuclear translocation of $\mathrm{NFKB}$, making it an attractive candidate for antifibrotic intervention.

\section{Suitability of other aminosalicylates against cardiac fibrosis?}

Besides mesalazine, sulfasalazine is frequently used to treat inflammatory bowel disease and rheumatoid arthritis. Sulfasalazine consists of sulfapyridine and mesalazine, which both have been shown to exert anti-inflammatory effect (Chávez et al. 2012). Sulfasalazine prevented induced hepatic fibrosis in a rat model by inhibiting nuclear NFKB translocation and the TGF $\beta$ pathway (Chávez et al. 2012). Therefore, it could be hypothesized that antifibrotic effects are also conceivable in the heart. However, there is currently no data available to support or refute this hypothesis. Irrespective of these similarities to mesalazine, the contained sulfapyridine frequently causes allergic reactions and is considered responsible for most of the side effects of sulfasalazine (Thornton and Mason 2012). Moreover, severe hematological side effects (blood dyscrasias), hepatitis, and male infertility have been reported more frequently than with mesalazine alone (Toovey et al. 1981; Ransford and Langman 2002). In summary, mesalazine appears therefore to be the more promising drug and our results indicate that mesalazine alone is sufficient for significant antifibrotic effects in vitro.

\section{Study limitations}

Using a cell line, beside its advantage of being phenotypically stable over many passages, always raises the question of how closely the immortalized cells are to native primary cardiac fibroblasts. Additionally, it is difficult to project towards systemic effects of drugs, judging from in vitro experiments. Table 2 summarizes common adverse effects of mesalazine used to treat inflammatory bowel disease (Ransford and 
Langman 2002; Klotz 2012; Böhm and Kruis 2014). Future research has to focus on the effects of mesalazine in vivo to determine cardiac antifibrotic benefits and potential systemic side effects. Despite these limitations, we are optimistic that mesalazine is a promising candidate for antifibrotic drug repurposing.

\section{Conclusion}

Here, we suggest that mesalazine may positively affect cardiac fibrosis - one of the most common causes of morbidity and mortality worldwide (Artlett 2012; Zhao et al. 2020). We found that mesalazine reduces fibroblast proliferation, myofibroblast differentiation, and collagen deposition after TGF $\beta$ induction. Furthermore, mesalazine ameliorated TGF $\beta$-induced changes in fibroblast mechanical properties, such as cell stiffness, stress relaxation, and cell adhesion. Finally, we shed new light on the molecular mechanisms of mesalazine: we propose dual inhibition of SMAD2/3 and ERK1/2 phosphorylation as a novel concept by which mesalazine may prevent cardiac fibrosis (Fig. 6). Additionally, we were able to validate the accepted mechanism of inhibiting NFKB activity. With years of documented clinical use, a favorable risk profile and low cost, we believe that mesalazine is an exciting candidate for further studies on drug repurposing to finally treat fibrosis.

Authors' contributions $\mathrm{MH}$ and TAK performed and designed experiments on fibroblast proliferation, protein expression, phenoconversion and nuclear translocation, analyzed data, and helped to prepare the manuscript. RE performed and analyzed experiments on fibroblast mechanical properties, collagen deposition, and helped to prepare the manuscript. JSER, MN, MS, KK, LW, and EK contributed to experiments and helped to prepare the manuscript. RP, UR, and AEA helped to improve the manuscript and designed experiments. SRK conceived the study, planned experiments, and wrote the manuscript. The authors declare that all data were generated in-house and that no paper mill was used.

Funding Open Access funding enabled and organized by Projekt DEAL. This study was funded by a "MeDDrive Start" grant by the faculty of Medicine Carl Gustav Carus Dresden (to SRK). RE, RP, and UR are members of the Collaborative Research Centre SFB1425 (DFG 422681845).

Data availability All data analyzed during this study are included in this article. All immunoblots are presented completely.

\section{Compliance with ethical standards}

Conflicts of interest The authors declare that they have no conflict of interest.

Open Access This article is licensed under a Creative Commons Attribution 4.0 International License, which permits use, sharing, adaptation, distribution and reproduction in any medium or format, as long as you give appropriate credit to the original author(s) and the source, provide a link to the Creative Commons licence, and indicate if changes were made. The images or other third party material in this article are included in the article's Creative Commons licence, unless indicated otherwise in a credit line to the material. If material is not included in the article's Creative Commons licence and your intended use is not permitted by statutory regulation or exceeds the permitted use, you will need to obtain permission directly from the copyright holder. To view a copy of this licence, visit http://creativecommons.org/licenses/by/4.0/.

\section{References}

Artlett CM (2012) The role of the NLRP3 inflammasome in fibrosis. Open Rheumatol J 6(1). https://doi.org/10.2174/ 1874312901206010080

Baum J, Duffy HS (2011) Fibroblasts and myofibroblasts: what are we talking about? J Cardiovasc Pharmacol 57(4):376-379. https://doi. org/10.1097/FJC.0b013e3182116e39

Böhm SK, Kruis W (2014) Long-term efficacy and safety of once-daily mesalazine granules for the treatment of active ulcerative colitis. Clin Exp Gastroenterol 7:369-383. https://doi.org/10.2147/CEG. S35691

Carmine Stolfi RP, Francesco Pallone GM (2008) Molecular basis of the potential of mesalazine to prevent colorectal cancer. World J Gastroenterol 14(28):4434-4439. https://doi.org/10.3748/wjg.14. 4434

Chávez E, Castro-Sánchez L, Shibayama M, Tsutsumi V, Moreno M, Muriel P (2012) Sulfasalazine prevents the increase in TGF- $\beta$, $\mathrm{COX}-2$, nuclear NFKB translocation and fibrosis in $\mathrm{CCl} 4$-induced liver cirrhosis in the rat. Hum Exp Toxicol 31(9):913-920. https:// doi.org/10.1177/0960327112438928

Cheng M, Wu G, Song Y, Wang L, Tu L, Zhang L, Zhang C (2016) Celastrol-induced suppression of the MiR-21/ERK signalling pathway attenuates cardiac fibrosis and dysfunction. CPB 38(5):19281938. https://doi.org/10.1159/000445554

Clemett D, Markham A (2000) Prolonged-release mesalazine: a review of its therapeutic potential in ulcerative colitis and Crohn's disease. Drugs 59(4):929-956. https://doi.org/10.2165/00003495200059040-00016

Desreumaux P, Ghosh S (2006) Review article: mode of action and delivery of 5-aminosalicylic acid - new evidence. Aliment Pharmacol Ther 24(s1):2-9. https://doi.org/10.1111/j.1365-2036. 2006.03069.x

Dong J, Ma Q (2019) In vivo activation and pro-fibrotic function of NF$\mathrm{KB}$ in fibroblastic cells during pulmonary inflammation and fibrosis induced by carbon nanotubes. Front Pharmacol 10:10. https://doi. org/10.3389/fphar.2019.01140

El-Armouche A, Wittköpper K, Degenhardt F, Weinberger F, Didié M, Melnychenko I, Grimm M, Peeck M, Zimmermann WH, Unsöld B, Hasenfuss G, Dobrev D, Eschenhagen T (2008) Phosphatase inhibitor-1-deficient mice are protected from catecholamineinduced arrhythmias and myocardial hypertrophy. Cardiovasc Res 80(3):396-406. https://doi.org/10.1093/cvr/cvn208

Emig R, Zgierski-Johnston CM, Beyersdorf F, Rylski B, Ravens U, Weber W, Kohl P, Hörner M, Peyronnet R (2019) Human atrial fibroblast adaptation to heterogeneities in substrate stiffness. Front Physiol 10:1526. https://doi.org/10.3389/fphys.2019.01526

Evans RA, Tian YC, Steadman R, Phillips AO (2003) TGF-beta1mediated fibroblast-myofibroblast terminal differentiation-the role of Smad proteins. Exp Cell Res 282(2):90-100. https://doi.org/10. 1016/s0014-4827(02)00015-0

Fan Z, Guan J (2016) Antifibrotic therapies to control cardiac fibrosis. Biomater Res 20:13. https://doi.org/10.1186/s40824-016-0060-8 
Fang L, Murphy AJ, Dart AM (2017) A clinical perspective of antifibrotic therapies for cardiovascular disease. Front Pharmacol 8. https://doi.org/10.3389/fphar.2017.00186

Guz N, Dokukin M, Kalaparthi V, Sokolov I (2014) If cell mechanics can be described by elastic modulus: study of different models and probes used in indentation experiments. Biophys J 107(3):564 575. https://doi.org/10.1016/j.bpj.2014.06.033

Hertz H (1882) Ueber die Berührung fester elastischer Körper. Journal für die reine und angewandte Mathematik 92:156-171

Hinderer S, Schenke-Layland K (2019) Cardiac fibrosis - a short review of causes and therapeutic strategies. Adv Drug Deliv Rev 146:7782. https://doi.org/10.1016/j.addr.2019.05.011

Hinz B, Celetta G, Tomasek JJ, Gabbiani G, Chaponnier C (2001) Alphasmooth muscle actin expression upregulates fibroblast contractile activity. Mol Biol Cell 12(9):2730-2741

Hinz B, McCulloch CA, Coelho NM (2019) Mechanical regulation of myofibroblast phenoconversion and collagen contraction. Exp Cell Res 379(1):119-128. https://doi.org/10.1016/j.yexcr.2019. 03.027

Huang ES, Strate LL, Ho WW, Lee SS, Chan AT (2011) Long-term use of aspirin and the risk of gastrointestinal bleeding. Am J Med 124(5):426-433. https://doi.org/10.1016/j.amjmed.2010.12.022

Jalife J, Kaur K (2015) Atrial remodeling, fibrosis, and atrial fibrillation. Trend Cardiovasc Med 25(6):475-484. https://doi.org/10.1016/j. tcm.2014.12.015

Jia G, Aroor AR, Hill MA, Sowers JR (2018) Role of RAAS activation in promoting cardiovascular fibrosis and stiffness. Hypertension 72(3):537-548. https://doi.org/10.1161/HYPERTENSIONAHA. 118.11065

Khalil H, Kanisicak O, Prasad V, Correll RN, Fu X, Schips T, Vagnozzi RJ, Liu R, Huynh T, Lee S-J, Karch J, Molkentin JD (2017) Fibroblast-specific TGF- $\beta-$ Smad2/3 signaling underlies cardiac fibrosis. J Clin Invest 127(10):3770-3783. https://doi.org/10. 1172/JCI94753

Klotz U (2012) The pharmacological profile and clinical use of mesalazine (5-aminosalicylic acid). Arzneimittelforschung 62(2): 53-58. https://doi.org/10.1055/s-0031-1299685

Künzel SR, Rausch JSE, Schäffer C, Hoffmann M, Künzel K, Klapproth E, Kant T, Herzog N, Küpper J, Lorenz K, Dudek S, Emig R, Ravens U, Rog-Zielinska EA, Peyronnet R, El-Armouche A (2020) Modeling atrial fibrosis in vitro-generation and characterization of a novel human atrial fibroblast cell line. FEBS Open Bio 10(7):1210-1218. https://doi.org/10.1002/2211-5463. 12896

Künzel SR, Schaeffer C, Sekeres K, Mehnert CS, Schacht Wall SM, Newe M, Kämmerer S, El-Armouche A (2019) Ultrasonicaugmented Primary adult fibroblast isolation. J Vis Exp 149. https://doi.org/10.3791/59858

Li X, Wang G, QiLi M, Liang H, Li T, E X, Feng Y, Zhang Y, Liu X, Qian M, Xu B, Shen Z, Gitau SC, Zhao D, Shan H (2018) Aspirin reduces cardiac interstitial fibrosis by inhibiting Erk1/2-serpine2 and P-Akt signalling pathways. CPB 45(5):1955-1965. https://doi.org/ 10.1159/000487972

Liu P-P, Liu H-H, Sun S-H, Shi X-X, Yang W-C, Su G-H, Zhao J (2017) Aspirin alleviates cardiac fibrosis in mice by inhibiting autophagy. Acta Pharmacol Sin 38(4):488-497. https://doi.org/10.1038/aps. 2016.143

Luedde T, Schwabe RF (2011) NF-kB in the liver-linking injury, fibrosis and hepatocellular carcinoma. Nat Rev Gastroenterol Hepatol 8(2): 108-118. https://doi.org/10.1038/nrgastro.2010.213

Luo S, Hieu TB, Ma F, Yu Y, Cao Z, Wang M, Wu W, Mao Y, Rose P, Law BY-K, Zhu YZ (2017) ZYZ-168 alleviates cardiac fibrosis after myocardial infarction through inhibition of ERK1/2dependent ROCK1 activation. Sci Rep 7(1):43242. https://doi.org/ $10.1038 /$ srep43242
McQuin C, Goodman A, Chernyshev V, Kamentsky L, Cimini BA, Karhohs KW, Doan M, Ding L, Rafelski SM, Thirstrup D, Wiegraebe W, Singh S, Becker T, Caicedo JC, Carpenter AE (2018) CellProfiler 3.0: next-generation image processing for biology. PLoS Biol 16(7):e2005970. https://doi.org/10.1371/journal. pbio. 2005970

Meng X, Nikolic-Paterson DJ, Lan HY (2016) TGF- $\beta$ : the master regulator of fibrosis. Nat Rev Nephrol 12(6):325-338. https://doi.org/10. 1038/nrneph.2016.48

Murtha LA, Schuliga MJ, Mabotuwana NS, Hardy SA, Waters DW, Burgess JK, Knight DA, Boyle AJ (2017) The processes and mechanisms of cardiac and pulmonary fibrosis. Front Physiol 8. https:// doi.org/10.3389/fphys.2017.00777

Park S, Nguyen NB, Pezhouman A, Ardehali R (2019) Cardiac fibrosis: potential therapeutic targets. Transl Res 209:121-137. https://doi. org/10.1016/j.trsl.2019.03.001

Paul SM, Mytelka DS, Dunwiddie CT, Persinger CC, Munos BH, Lindborg SR, Schacht AL (2010) How to improve R\&D productivity: the pharmaceutical industry's grand challenge. Nat Rev Drug Discov 9(3):203-214. https://doi.org/10.1038/nrd3078

Poulet C, Künzel, Stephan, Büttner E, Lindner D, Westermann D, Ravens U (2016) Altered physiological functions and ion currents in atrial fibroblasts from patients with chronic atrial fibrillation. Phys Rep 4(2). https://doi.org/10.14814/phy2.12681

Pushpakom S, Iorio F, Eyers PA, Escott KJ, Hopper S, Wells A, Doig A, Guilliams T, Latimer J, McNamee C, Norris A, Sanseau P, Cavalla D, Pirmohamed M (2019) Drug repurposing: progress, challenges and recommendations. Nat Rev Drug Discov 18(1):41-58. https:// doi.org/10.1038/nrd.2018.168

Ramadan A, Afifi N, Yassin NZ, Abdel-Rahman RF, Abd El-Rahman SS, Fayed HM (2018) Mesalazine, an osteopontin inhibitor: the potential prophylactic and remedial roles in induced liver fibrosis in rats. Chem Biol Interact 289:109-118. https://doi.org/10.1016/j. cbi.2018.05.002

Ransford RAJ, Langman MJS (2002) Sulphasalazine and mesalazine: serious adverse reactions re-evaluated on the basis of suspected adverse reaction reports to the Committee on Safety of Medicines. Gut 51(4):536-539

Reinacher-Schick A, Seidensticker F, Petrasch S, Reiser M, Philippou S, Theegarten D, Freitag G, Schmiegel W (2000) Mesalazine changes apoptosis and proliferation in normal mucosa of patients with sporadic polyps of the large bowel. Endoscopy 32(3):245-254. https:// doi.org/10.1055/s-2000-135

Rockey DC, Bell PD, Hill JA. 2015. Fibrosis - a common pathway to organ injury and failure.: https://doi.org/10.1056/ NEJMra1300575.

Rosenbloom J, Mendoza FA, Jimenez SA (2013) Strategies for antifibrotic therapies. Biochim Biophys Acta (BBA) - Mol Basis Dis 1832(7):1088-1103. https://doi.org/10.1016/j.bbadis.2012.12.007

Schindelin J, Arganda-Carreras I, Frise E, Kaynig V, Longair M, Pietzsch T, Preibisch S, Rueden C, Saalfeld S, Schmid B, Tinevez J-Y, White DJ, Hartenstein V, Eliceiri K, Tomancak P, Cardona A (2012) Fiji: an open-source platform for biological-image analysis. Nat Methods 9(7):676-682. https://doi.org/10.1038/nmeth.2019

Schroer AK, Merryman WD (2015) Mechanobiology of myofibroblast adhesion in fibrotic cardiac disease. J Cell Sci 128(10):1865-1875. https://doi.org/10.1242/jcs.162891

Sertkaya A, Wong H-H, Jessup A, Beleche T (2016) Key cost drivers of pharmaceutical clinical trials in the United States. In: Key cost drivers of pharmaceutical clinical trials in the United. Clinical Trials, States. https://doi.org/10.1177/1740774515625964

Tallquist MD, Molkentin JD (2017) Redefining the identity of cardiac fibroblasts. Nat Rev Cardiol 14(8):484-491. https://doi.org/10. 1038/nrcardio. 2017.57

Thornton C, Mason JC (2012) Chapter 16 - Drugs for inflammation and joint disease. In: Bennett PN, Brown MJ, Sharma P (eds) Clinical 
Pharmacology, Eleventh edn. Churchill Livingstone, Oxford, pp 240-259. https://doi.org/10.1016/B978-0-7020-4084-9.00055-0

Toovey S, Hudson E, Hendry WF, Levi AJ (1981) Sulphasalazine and male infertility: reversibility and possible mechanism. Gut 22(6): 445-451. https://doi.org/10.1136/gut.22.6.445

Uygur A, Lee RT (2016) Mechanisms of cardiac regeneration. Dev Cell 36(4):362-374. https://doi.org/10.1016/j.devcel.2016.01.018

Walsh JE, Young MRI (2011) TGF-beta regulation of focal adhesion proteins and motility of premalignant oral lesions via protein phosphatase 1. Anticancer Res 31(10):3159-3164

Weil J, Colin-Jones D, Langman M, Lawson D, Logan R, Murphy M, Rawlins M, Vessey M, Wainwright P (1995) Prophylactic aspirin and risk of peptic ulcer bleeding. BMJ 310(6983):827-830. https:// doi.org/10.1136/bmj.310.6983.827

Yoshizaki A, Yanaba K, Iwata Y, Komura K, Ogawa A, Akiyama Y, Muroi E, Hara T, Ogawa F, Takenaka M, Shimizu K, Hasegawa M,
Fujimoto M, Tedder TF, Sato S (2010) Cell adhesion molecules regulate fibrotic process via Th1/Th2/Th17 cell balance in a bleomycin-induced scleroderma model. J Immunol 185(4):25022515. https://doi.org/10.4049/jimmunol.0901778

Zhang Z, Li S, Deng J, Yang S, Xiang Z, Guo H, Xi H, Sang M, Zhang W (2020) Aspirin inhibits endometrial fibrosis by suppressing the TGF- $\beta 1$-Smad2/Smad3 pathway in intrauterine adhesions. Int $\mathrm{J}$ Mol Med 45(5):1351-1360. https://doi.org/10.3892/ijmm.2020. 4506

Zhao X, Kwan JYY, Yip K, Liu PP, Liu F-F (2020) Targeting metabolic dysregulation for fibrosis therapy. Nat Rev Drug Discov 19(1):5775. https://doi.org/10.1038/s41573-019-0040-5

Publisher's note Springer Nature remains neutral with regard to jurisdictional claims in published maps and institutional affiliations. 